\title{
Perception of Nurses toward Nursing Leadership as an Influential Factor to Better Healthcare Outcome
}

\author{
Udo Orukwowu* and Janet Ene-Peter
}

\author{
Department of Nursing Sciences, Faculty of Basic Medical Sciences, College of Medical Sciences, Rivers State University,
}

Nigeria.

*Corresponding author email: udocd27@gmail.com; Phone: +2349060039098

\begin{abstract}
The research study is basically on the perception of Nigerian nurses towards nurse leadership as an influential factor to better healthcare outcome. This research study was a qualitative research study underpinned with the philosophy of ethnography. Thematic analysis was used to analyse the ethnographic interview data. A purposive convenient sampling was employed to ensure the right people were recruited and interviewed at their convenience to ensure enough time was given to the interview process, to allow in-depth exploration of information from the participants. The study sample size was eight. The participant were known by the researcher and were only selected with the inclusion criteria which includes only Nigerian nurses in the University of Sunderland, nurses that have been or are in the position of a nurse leader and have practice for more than ten years. Consequently, ethnographic interview was conducted with a face-to-face semi-structured open ended question to able to explore into the nurses experience. Data collection was through audio tape recorder, transcribed and analysed using thematic analysis. Conclusively, the key themes formed the discussion of the findings. The key themes emerged from the subthemes. The themes were generated from the data collected from the participants according to the information they gave which answered the research question to give the desired result. However, the data collected from the ethnographic interview were strengthened by theories and literatures to give a final report. Therefore, the support from theory and literature confirmed the findings of the study. As a result, the study revealed that nursing leadership has an enormous influence on better healthcare outcome, through their roles and performances to ensure quality care. Hence, the perception of nurses indicates that nursing leadership is an influential factor to better healthcare outcome.
\end{abstract}

\section{Article History}

Received: 15 Jan 2022

Accepted: 05 Feb 2022

Published: 07 Feb 2022

\section{Scan $Q R$ code to view}
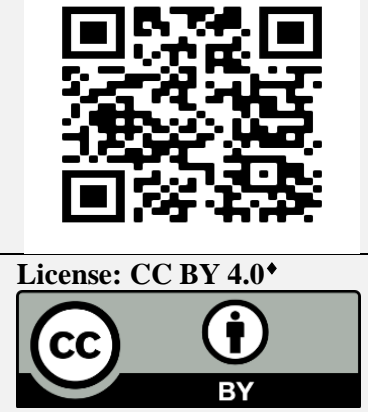

Open Access article.

Keywords: $\quad$ Nursing, Leadership style in nursing, Nursing leadership, Healthcare outcome

How to cite this paper: Orukwowu, U. (2022). Perception of Nurses toward Nursing Leadership as an Influential Factor to Better Healthcare Outcome. IPS Journal of Public Health, 1(1), 1-15. https://doi.org/10.54117/ijph.v1i1.2.

\begin{abstract}
1. Introduction
Nursing leadership is very crucial in the improvement of patients' care and safety in the ward and around all healthcare environments (Feldman et al., 2012; Sfantou et al., 2017; Cummings et al., 2021). As a result, there has been ongoing research theoretically underpinning an ethnographic approach on how nursing leadership affects healthcare outcomes (Cummings, 2011; MorganTrimmer and Wood, 2016). However, according to Murphy (2009), nursing leadership in the healthcare sector is crucial due to its contribution in the provision of effective patient care. Currently, due to the quest for better leadership skills in the improvement of patient care, senior nurses now engage in different levels and roles of leadership activities in their everyday routine to bring about changes in the performance of their daily activities (Edmonstone, 2008). However, some other senior nurses have found it difficult to understand the concept of leadership thereby bringing variations in nursing leadership and how it affects healthcare outcome (Feldman et al., 2012; Armstrong et al., 2020).
\end{abstract}

Edmonstone (2008) reported that nurse leaders take contradictory approaches to their leadership roles especially meeting short term targets and corporate goals. Therefore, it has necessitated nurses who take leadership roles in the clinical setting to acquire not only academic based knowledge and skills, but should also require trainings and experiences regarding political, creative and financial aspects in their roles to competently and proficiently enhance nurse leadership role (Sanford 2010; Kelly, 2012). Nursing leadership has become very essential but challenging in diverse way (Swansburg, 2002; Cummings et al., 2021). Essentially, to overcome the prevailing challenges of leadership in any healthcare environment, Roussel (2011), argued that it is essential for nurses to establish the atmosphere for creativity as well as creative problem solving strategies

However, despite the qualities the nurse leaders equip themselves with, they also anticipate potential or encounter actual failures that will or might negatively affect healthcare outcome (Hickey and Kritek, 2012). Therefore, nurse leadership could sometimes lead to good or bad effects of healthcare outcomes (Greenberg, 2013). On this regard, nurse leaders has been prompted to address issues of successful change in their practices to enhance better healthcare outcome (Roussel, 2011; Greenberg, 2013; Hickey and Kritek, 2012). This study examined the perception of nurses regarding nursing leadership as an influential factor for better healthcare outcomes.

\section{Methodology}

\subsection{Ethical Consideration}

Due to ethical principles, informed consent is very critical (Houghton et al., 2010; Hammersley and Traianou, 2012). During the interview process, the researcher was constantly negotiating with the informants. This negotiation 
took place as the "informed process consent" which carries on all through the research process and allows for possible revise arrangements (Savin-Baden and Major, 2010; Miller et al., 2012). Significantly, participants collaborate with the researcher in their ongoing participating decisions (Klenke, 2008; Love, 2012). Therefore, participants are given the right to the study at any time of their choice, with great rregardto their "voluntary autonomy dimensions" as supported by Houghton et al. (2010) and Wiley (2013).

\subsection{Population Identification}

Basically, the research study is based on nursing leadership in Nigeria. In Nigeria, nurses are graded in the following positions; Nursing Officer II (NOII), Nursing Officer I (NOI), Senior Nursing Officer (SNO), Principa Nursing Officer (PNO), Assistant Chief Nursing Officer (ACNO), Chief Nursing Officer (CNO), Deputy Director of Nursing Services (ADNS) and Director of Nursing Services (DNS). Therefore, nurse leadership is of differen cadre. Nurses start being in-charge in the ward and acts as nurse leaders from the NOII depending on the strength of staff and the situation of the hospital whether in the urban or rural setting. As a result, nurse leadership exists at al levels of nursing practice. For this reason, nurses that have assumed any level of leadership position will be employed to participate in this study.

The population comprises of only Nigerian nurses. Therefore, the researche sorted for Nigerian nurses that are studying in the University of Sunderland who have acted as a nurse leader to participate in the study. The underlying principle of choosing just nurses that have acted as nurse leader is because the focus of the study is on nurse leadership and needs the views of nurses that have served in such capacity. As a result this study will require on Nigerian nurses offering either of BSc (Hons) Nursing or MSc Nursing to participate and offer their perceptions as how nurse leadership affects better healthcare outcome.

\subsection{Sampling}

Significantly, there is a great differentiation in qualitative and quantitative sampling (Klenke, 2008). However, Speziale et al. (2011) emphasized that the larger sample sizes in quantitative research methods makes it generalizable unlike qualitative research studies that goes with smaller sample sizes. Qualitative sampling size has its own strengths and values (Quimby, 2012). As a result, Ulin et al. (2012) argued that, qualitative sampling provides richness and exploratory value in its data which is considered very important

Furthermore, Quimby (2012:130) also added that qualitative small sample size has an advantage of "in-depth exploration of data", "in-depth analysis of themes" including "detailed patterns of meaning". Therefore, Sue (2010) and Saini and Shlonsky (2012) indicated that an acceptable range of sample for a qualitative data is between $6-10$ participants (Sue, 2010) which is applicable to this research study. However, constant comparative method was applied due to interview schedules being modified before a subsequent interview is performed to enrich the interview data; this is as a result of new themes emerging (Kolb, 2012)

\subsection{Sampling Technique}

To achieve the purpose of this research study, a purposive sampling technique (Gerrish and Lacey, 2013) was adopted throughout the process of data collection. The rationale for purposive sampling relies on hand picking participants that are knowledgeable and relevant in participating (Holloway, 2013; Denscombe, 2010). According to Denscombe (2010), purposive sampling requires experts from specific group purposely sought and sampled to gain information and knowledge required to answer the research question (Ray, 2012). Basically, the researcher knows the background of the participants before sampling them for the study as supported by Gerrish and Lacey (2013). However, to enhance the exploration of the research question, a kind of purposive sampling which is convenience sampling was added. Therefore, a purposive convenience sampling (Takeuchi, 2008) will ensure the right people were recruited and interviewed at their convenience to ensure that enough time was given to the interview process, to allow in-depth exploration of information from the participants. To ensure convenience, arrangements were made with the participants to arrange for an appropriate date and time as well as the venue for the interview.

\subsection{Recruiting Participants}

Participants were recruited through purposive convenience sampling to address the research question with a wealth of information because they have been known by the research and are experts regarding what is being studied, therefore, can give the needed information to answer the research questions.
Basically, the participants were drawn from the BSc Nursing and the MSc Nursing courses respectively. The selection criteria were based on nurses with leadership experience. Therefore, senior nurses that have assumed leadership positions on were selected for the study. The selected participants were given a briefing of the study. However, this was done after the ethical issues has been sorted; where the participants sign an informed consent and were informed about the details of the study to keep them aware of their involvement. After their full consent has been sort, a schedule for an interview meeting was agreed upon. Moreover, confidentially was assured and freedom to declined was also communicated and assured.

\subsection{Interview Process / Data Collection}

In ethnography, data collection and its analysis occur simultaneously (Silverman, 2011). Ethnographic Interview was used in this study. It has been regarded as an important part in ethnographic data gathering techniques with a semi-structured interview to gain deeper knowledge and understanding of the specific culture (Fetterman, 2010). In this stage, the participant's responses were being mapped by the researcher. According to Cruz and Higginbottom (2013), to enhance a good ethnographic research in a healthcare setting, researcher considers all the bits in the explanations, experiences as well as the appearance of the participants, (Murchison, 2010; Speziale et al., 2011). Data was collected through an open ended semi structured interview. An open ended semi structured questions was administered and explored further with the participants by asking further questions as more other ideas emerged from the participants.

\subsection{Data Analysis}

As a qualitative ethnographic research studies, data analysis starts from the time of data collection (Speziale and Carpenter, 2007; Speziale and Carpenter, 2011). Essentially, the researcher listened carefully to hear the experiences of the participants to be able to read and discover meanings. The researcher engaged in interviews continuously to gain additional information, asking questions that can lead to other questions from the responses of the interviewee as supported by Speziale and Carpenter (2007) and Firth (2013).

Due to the fact that in ethnography research studies data analysis starts from the stage of data collection (Speziale et al., 2011). Therefore, thematic analysis was the method of choice for analysing the collected ethnographic data for this study. According to Srivastava and Thomson (2009) thematic analysis is suitable for an ethnographic data analysis due to its flexibility. It has been argued that it also enhances trail of audit transparency, maintains credibility and rigor of research results (Lyons and Coyle, 2007; Smith and Firth, 2011). This process of data analysis helps the researcher in understanding and interpreting data effectively (Fuber, 2010; Speziale et al., 2011). Thematic data analysis has been discussed in more details in chapter four.

\section{Results}

The data analysis and findings of the research study is presented in this chapter. Thematic analysis was employed to analyse the ethnographic data, and the process of the analysis will be discussed. Thematic analysis and the process of analysing data with thematic analysis will be addressed. There will be identification of themes and sub-themes. Basically, thematic analysis will be used to enhance the analysis of the ethnographic data collected.

\subsection{The Process of Data Analysis}

Ethnography is a distinct way in which research can be done aimed at understanding a way of life of a social group focusing on their daily lived experiences with an in-depth interview (Scott-Jones and Watt, 2010). However, Steen and Roberts (2011) established that the analysis of ethnographic data can follow thematic analysis process where the interviews will be transcribed and analysed for formation of possible themes and meanings (Steen and Roberts, 2011). This is done to give a better understanding to the data collected. Therefore, thematic analysis is employed to analyse the ethnographic data in this study.

According to Scott-Jones and Watt (2010), thematic analysis is used in ethnographic study as the key method of transforming data into their explicit codes. And data will be encoded into themes (Steen and Roberts, 2011) and the key themes will be drawn and theoretically framed to give them more meaning (Carollo, 2012). Significantly, the application of thematic analysis is built on three distinctive stages: 
- Deciding on the specific sampling criteria and issues of research design

- Development of themes and codes

- Validating and using thematic codes

However, in the second stage, thematic codes are developed in other three ways which includes;

- Theory driven

- Prior data or prior research driven

- Inductive (which is from raw data) or data driven (Boyatzis, 1998).

However, based on the three distinct stages involving thematic codes, there are also six phases to perform the process of coding in thematic analysis, where meaning patterns will be established (Bigi, 2012). These six phases includes the following;

$\checkmark \quad$ Getting familiarized with data

$\checkmark$ Generation of initial codes

$\checkmark$ Searching for themes among codes

$\checkmark$ Reviewing themes

$\checkmark$ Defining and naming themes and

$\checkmark \quad$ Producing a final report.

(Braun and Clarke, 2006; Carollo, 2012).

Table 1 shows the demographic details which indicates the inclusive criteria for the study. Participants were identified as Participant A, B, C, D, E, F, G and H, making it eight (8) participants. The participants that were selected were those that has good competency in nursing practice due to their long years of experience and had also had leadership experience as a nurse leaders. Those nurses that has not practice as in the capacity of a nurse leader were excluded. Therefore, I made sure the selected participants had nurse leadership experience and also had more than ten years of experience in nursing practice to be able to achieve the objectives of the research as well as being able to answer the research question. Generally, it only included Nigerian nurses based on nurse leadership concepts in Nigeria.

Table 1: Demographic details of the participants

\begin{tabular}{llll}
\hline Participants & Sex & Age & $\begin{array}{l}\text { Years of } \\
\text { experience }\end{array}$ \\
\hline A & F & 45 & 21 \\
B & M & 38 & 15 \\
C & F & 42 & 12 \\
D & F & 38 & 14 \\
E & F & 47 & 18 \\
F & F & 40 & 16 \\
G & F & 41 & 15 \\
H & F & 48 & 22 \\
\hline
\end{tabular}

Consequently, the selected participants were interviewed and their interviews were audiotaped. After the interview, the mass of words that was generated from the verbatim recorded interview was also transcribed verbatim. According to (Edwards and Skinner, 2009), verbatim transcription of audiotaped interview ensures reliability of the collection and analysis of data in an ethnographic qualitative research study. Therefore, the verbatim transcription of the interview will ensure core themes Meleis (2010). However, in this research study, analysis was a continuous process, indicating the analysis started from the data collection stage. This is why Thematic Analysis was employed because it has flexibility as a benefit for application as was established by Braun and Clarke (2006). As a result, each interview was broken down into units of data, examined together as a block of information, condensed, categorised and interpreted, making them more meaningful (Klenke, 2008; Folkestad, 2008).

However, following the steps of steps of thematic analysis as mentioned above, the researcher was able to familiarize with the interview data by reading them over and over again, making essential notes from the main points. Furthermore, there was a line by line examination of the generated data in the process of familiarizing with the data. Hence, the initial codes were generated and driven to themes as the interview went on. Subthemes were emerging (see example from the appendix) from each interview to form the key themes.

\subsection{Categorizing subthemes under emerged key themes}

According to Bryman (2013:554), "a theme is more or less the same as code" in the principles of thematic analysis. Therefore, in this study there is no distinct between identifying of themes and coding. However, themes with the same concept and meaning will be categorized under a key theme, depending on the recurrence of the themes, making the other themes as subthemes to facilitate analysis and making sense of the emerged interview data. Hence, related key themes and subthemes as below have emerged from the data for analysis:

\section{Key theme one:}

A) Impact of how nurse regard leadership:

Following subthemes:

A1) influencing others

A2) Overseeing all activities

A3) Attaining a standard goal

Key theme two:

B) Impact of effective communication

Following subthemes:

B1) good flow of communication

B2) Modes of communication

B3) Transparency

\section{Key theme three:}

C) Impact of training

Following subthemes:

C1) Regular training

C2) Continuous professional development (CPD)

\section{Key theme four:}

D) Impact of proficiency in practice

Following subthemes:

D1) evidence based practice

D2) Quality assurance

D3) clinical skills

\section{Key theme five:}

E) Impact of interpersonal relationship

Following subthemes:

E1) Support from both staff and patients

E2) Cordial relationship

E3) Cooperativeness

E4) rapport with co-workers

\section{Key theme six:}

F) Impact of leadership styles

Following subthemes:

F1) Use of democratic leadership styles

F2) Use of Autocratic leadership styles

F3) Flexibility and situational application of leadership styles

Key theme seven:

G) Impact of leadership role

Following subthemes:

G1) Role model and mentor

G2) Supervision

G3) Transparency

G4) Monitoring

G5) Delegation of duties

G6) Strategizing and prioritizing activities

G7) Responsibility and accountability

Key theme eight:

H) Impact of emotional intelligence

Following subthemes:

H2) Encouragements 


\section{H4) Addressing personal issues}

Key theme nine:

I) Impact of effective care management

Following subthemes:

I1) Patient centred care

I2) Quality and standard practice

I3) Care plan

I4) Reflective practice

Key theme ten:

J) Impact of improvement strategies

Following subthemes:

J1) Appraisals

J2) Benchmarking

J3) Performances

Key theme eleven:

K) Impact of managerial skills:

Following subthemes:

K1) Teamwork

K2) Skill mix and staff availability

K3) Discipline

K4) Organising and coordinating

K5) Provision of needs

\subsection{Significance of the emerged themes and subthemes}

The strategy employed is to thematically analyse the ethnographic qualitative data that emerged from a qualitative interview. Basically, the theme and subthemes that emerged are the motifs that reoccurred and identified in the interview to ascertain the perception of nurse leaders towards leadership as a factor to better health outcomes. According to Bigi (2012), themes generally appear as salient idea in the interview data. The application of inductive and deductive thinking will enhance interpretation to give meaning to the data (Rowles and Schoenberg, 2002). However, to support and facilitate interpretation, verbatim quotes will be applied to key themes to enhance the data analysis. Therefore, the essential information given by the participants will be presented under the subthemes that made up the key themes as below;

\subsection{The impact of how nurses regard leadership}

The impact of how nurses regard leadership as a key theme has the following as subtheme; influencing others, overseeing activities, attaining a standard. In the course of my interview, the researcher noticed that the nurses gave different meanings to leadership, and that the meanings they give also affect their performances as nurse leaders. Their ideas were as follows;

\subsubsection{Influencing others}

"Nursing leadership is to influence others to get things done in an organised way" (Participant A).

"Emm.... What I understand by nursing leadership is the ability to influence your followers" (Participant F).

"to influence my staff to motivate them, to support them to make sure the work is being done" (Participant G).

\subsubsection{Attaining a standard goal}

"The capacity to carry followers along in their course of duty to attain a standard goal, so that the quality of care given to their patients is of a higher standard" (Participant B).

\subsubsection{Overseeing all activities}

"To me, nursing leadership is just the ability of the nurse to oversee all the activities of the staffs" (Participant $\mathrm{C}$ ).
"To lead people in the right way" (Participant D).

"Nursing leadership is about ensuring that everything is done in order to help the patient recover or in order to give good healthcare to the patients. Ensuring that everything is done in an organised systematic way to get a good outcome" (Participant $\mathrm{H}$ ).

\subsection{Impact of communication}

The impact of communication as a theme has the following subthemes as good communication flow, mode of communication and transparency. The researcher observed the communication is an enormous factor in healthcare practice which needs great attention among healthcare workers. However, not many of the participants made comments on impact of communication to better leadership outcome. Below are some verbatim quotes on communication;

\subsubsection{Good communication flow}

"I ensure effective communication between me and other staff as well as between staffs, for effective application of roles" (Participant C).

"I ensure effective communication for things to be done in the proper manner" (Participant D).

"The leader must be able to communicate properly with their subordinate, so that they will be able to take good care of the patient, and also be able to communicate with other healthcare professionals. With effective communication things will work fine, because a situation whereby there is no adequate communication the multidisciplinary team will not be able to express their feelings regarding patients' care" (Participant D).

\subsubsection{Mode of communication}

"For effective application of roles, I employ one-way or two-ways mode of communication as the case may be" (Participant $\mathrm{C}$ ).

\subsubsection{Transparency}

"Also, I ensure transparency in all levels of communication to enhance better patient care" (Participant D).

Our relationship is evidenced by open communication, good flow of communication with my subordinates (Participant F).

"I am somebody who would not be impartial in my relationships and communication" (Participant G).

\subsection{Impact of interpersonal relationship:}

Impact of interpersonal relationship in enhancing better healthcare outcome was derived from the following subthemes such as Supports, cordial relationships, cooperativeness, and rapport with co-workers. Responses from the participants have shown a great relationship between communication and interpersonal relationship. Therefore, maintaining good interpersonal relationship will greatly influence communication system.

\subsubsection{Cordial relationship}

"Relationship has a lot do with positive outcome, if there is no good and proper relationships there won't be proper communication; meaning there will be gap in communication. So as a leader I communicate properly with my subordinates, so that they will be able to take good care of the patient, and also be able to communicate with other healthcare professionals to enhance better healthcare outcome within the multidisciplinary team" (Participant D). 
"I must respect everyone ensuring work is been done adequately. Relationship must be cordial for staff to perform their duties. The relationship must be centred upon the work which is to care for the patients. The relationship should be centred in the patients' best interest" (Participant G).

"Our relationship is cordial and professional" (Participant B).

\subsubsection{Cooperativeness}

"With effective communication, things will work fine, because a situation whereby there is no adequate communication the multidisciplinary team will not be able to express their feelings regarding patients' care. Therefore, I maintain good relationship to enhance good communication which will enhance management of care" (Participant D).

"I also ensure good relationship between me and other staffs and as well as between staffs to make a better teamwork and to enhance better health outcome through performance" (Participant C).

"teamwork is very essential which is fostered by good relationship. Therefore, I encourage good relationship and effective team work among my staff to attain the organisational goals" (Participant C).

\subsubsection{Rapport with co-workers}

"Since effective care of patient is the expected performance in the healthcare sector, as a nurse leader I ensure effective nurse patient relationship. Hence, establishing good nurselpatient relationship will enhance goal achievement, improving on clinical and professional skills to ensure quality care. Engage in evidence based practice and implementing in the ward" (participant D).

"Our relationship is evidenced by open communication, good flow of communication with my subordinates, I don't trash them down, I communicate with them in the language they will understand. I maintain cordial relationship with them, even with the other multidisciplinary team" (Participant F).

"There is good relationship with majority of the staff and we enjoy working together" (Participant $\mathrm{H}$ ).

"I have seen my staff maintaining good and cordial relationship with other healthcare practitioner to be able to provide effective care within the multidisciplinary team" (Participant A).

"Well, due to the rapport and the relationship that exists between me and the staffs, I will say they are very supportive and they are corporative as well, I have not had any problem with anybody" (Participant E).

\subsection{Impact of leadership styles:}

Nurses have demonstrated how the impact of application of leadership styles has enhance their practice, thereby enabling better healthcare outcome. Impact of leadership style as a team was derived from the following subthemes such as use of democratic leadership styles, use of autocratic leadership style and Flexibility and situational application of leadership styles.

\subsubsection{Use of democratic leadership styles:}

"Sometimes, I apply the democratic style of leadership where I seek their opinion so that we can have better outcome by working together" (Participant C).

"....sometimes I have to be democratic to involve them in decision making for them to feel responsible in the performance of their daily duties" (Participant $\mathrm{H}$ ).

\subsubsection{Use of Autocratic leadership styles:}

"...sometimes I apply command which is an autocratic kind of leadership as the strategy to facilitate better performance" (Participant C).

"Mostly, I apply autocratic leadership style because I have to have a firm hand, because most of my subordinate would not want to submit especially with the older colleagues, so I have to say something and stand by it. I will say I am more of autocratic" (Participant E).

"... because there are certain times when I need to be autocratic to make sure certain tasks are performed" (Participant $\mathrm{H}$ ).

\subsubsection{Flexibility and Situational application of leadership styles}

"I make sure that both democratic and autocratic leadership are being practised, because there are some grounds that I need to be democratic, I give them the opportunity to bring out options of how to get a particular task done. But sometimes I have to be autocratic, especially to do thing the best way because I don 't compromised not doing things the best way in the ward so as to achieve a better health outcome" (Participant A).

"Generally I am very flexible in applying my leadership styles to achieve desirable outcomes” (Participant A).

"To influence my subordinates, I tend to be flexible, using democratic leadership styles but sometimes I employ the autocratic style of leadership especially when things are supposed to be done in the right manner. Basically, the application of leadership styles depends on the situation at hand" (Participant B).

"Situation warrants how I apply my leadership styles and skills. For example, if the staffs I have under me are performing very poor,

sometimes I apply command which is an autocratic kind of leadership as the strategy to facilitate better performance" (Participant C).

"Application of leadership skills according to situation, for example, applying the autocratic style of leadership when the need arises, as well as the democratic when the need arises" (Participant F).

"Sometimes I may be flexible to effectively manage certain issues" (Participant G)

"....if I don't use flexibility sometimes, that may be a kind of stress and storm within the clinical environment” (Participant G).

"I also apply autocratic, especially when things are supposed to be done right and orderly" (Participant $\mathrm{H})$.

\subsection{Impact of training}

Impact of training has been identified by the participants as a measure for improved performance. The verbatim quotes from the participants are indicated under the following subthemes;

\subsubsection{Regular training}

"I make sure that lectures and symposium are organised for the staff time to time, to update them to ensure that the actually know the reason why a particular style of ways of rendering Care is being adopted" (Participant A)

"I improve my performances by attending leadership workshops, seminars" (Participant B).

"Nurse leader affect health outcome by encouraging staff to attend regular training and courses to attain the trend in the profession by 
acquiring the required skills to be applied in practice which assures quality care and better health outcome" (Participant B).

"I also encourage them to undergo professional specialisation to be able to master skills in a particular area to be able to apply the best practice to enhance better outcome" (Participant B).

"I try to motivate them and engage them in necessary trainings so that everyone will be updated in the care of patients" (Participant C).

"Nursing leader is someone that acquires the training in leadership skill that is able to lead people in the right way" (Participant D).

"I improve my performance through attending workshops and trainings on leadership and professional skills" (Participant D).

"We go for occasional training and retraining also make sure that the staff under me are up-to-date in the training they are supposed to undergo" (Participant E).

\subsubsection{Continuous professional development (CPD)}

"I improve my performance my engaging myself with continuous professional development, benchmarking and trying to know what is happening in other disciplines" (Participant F).

“... and also engage in lifelong learning. Basically, I depend on evidence based practice, therefore I engage myself with research to find out the recent practices in the profession as well as in nursing leadership. I also encourage my subordinates to engage in further studies and evidence based practice to sharpen their skills to promote quality care" (Participant B).

".... I also encourage my staff to participate in current health care delivery through further studies because I believe evidence based practice influences better health outcome through quality care delivery" (Participant B)

"I encourage my subordinates to engage in trainings to enhance their clinical skills. And encourage them to undergo further education and lifelong learning" (Participant C).

"To improve my skills, I engage in trainings lifelong learning, continuous professional development (CPD)" (Participant $\mathrm{C})$.

"I encourage my subordinates to perform better through engaging in lifelong learning to keep their skills up-to-date” (Participant F).

"I engage myself in lifelong learning; I try to be up-to-date with my clinical skills through research and reading journals" (Participant F).

\subsection{Impact of competency}

Competency has been seen to have great impact in delivering quality care and achieving better health outcome. Nurses have testified that attaining competency enhances performance and being able to do those things that will enhance achieving organisational goal. Impact of competency was derived from subthemes such as best practice and improved clinical skills. Therefore, the nurses' view will be given under the subthemes as below;

\subsubsection{Best practice}

"My role as a nurse leader is to ensure the smooth running of the ward and also ensure that staffs attends an update courses regularly to sharpen their skills and be in touch with current mode of practices" (Participant B).
"Competency is promoted, therefore, case of negligence is not to be tolerated in the ward, cases of negligence should be reported, because they have actually led to thousands of death as we have seen in previous report" (Participant B).

“.... by practicing the right thing and making sure you acquire the right skills because if you don't have the right skills, there is no way you will be able to implement it, therefore, competent leader will be able to direct the subordinates in the right way to work towards the organisational goal" (Participant D).

“... I believe that nurses play a key role in making sure that patients gets the best possible care they can get in the hospital, so I'll say that by ensuring a good leadership, it would ensure that the patient receives good and adequate care" (Participant E).

"...I must be able to see that the qualities of care the patients are receiving are really the first class care, they must get a better quality care from nurse" (Participant G)

\subsubsection{Improved clinical skills}

“....nursing leadership means someone that is experienced, skilled and has the capacity to carry followers along in their course of duty to attain a standard goal, so that the quality of care given to their patients is of a higher standard" (Participant B).

"Since the all healthcare settings are to achieve a better healthcare outcome, so as the nurse leader I require all necessary skill to attain better health outcome in the healthcare setting" (Participant C).

“......ensure improving on clinical and professional skills to ensure quality care” (Participant D).

"I engage in evidence based practice and also implement it in the ward to ensure better patient care" (Participant D).

"....it's good for nurse leaders equip themselves with the up-to-date clinical skills to enhance evidence based practice” (Participant F).

\subsection{Impact of improvement strategies}

The impact of improvement strategies has been seen as a means to provide quality healthcare to enhance better healthcare outcome. The key theme is derived from the following subthemes such as appraisals, benchmarking and performance. The information from the participants has been outline under the subtheme as below;

\subsubsection{Appraisals}

"...there is a particular suggestion box that has been placed at the entrance corner of every ward for people to indicate if they are satisfied with the services rendered, and what they want us to improve upon" (Participant A)

"ermm...yeah, I evaluate my performances by appraisals according to our set goal, like I said, there is a set goal for the ward as well as for each patient, we carry out an appraisal and check if the goals were met. (Participant B).

"...I try to listen to views of others through their suggestions and feedback and appraisals, and then I will be able to apply corrective measures to improve performance" (Participant C).

"How I evaluate my performance is by getting a feedback from my subordinates, even from the patients because the patients also knows 
when things are not being done the right ways, as well as the use of appraisals... "(Participant F).

"Another way of improving my performance is also to get feedbacks from staff appraisals and patients' feedbacks from the suggestion box. What they say about me and things they feel are not right will be acted upon' (Participant G).

\subsubsection{Benchmarking}

"From all the feedback, questionnaires, suggestion box, I evaluate, measure and benchmark all my performances to know how well it has been and where to improve" (Participant C).

"Umm ...how I can improve my organisational goal is by setting a target, working towards it, evaluating what I've done, ensuring that the set target is met, I re-evaluate if I feel the target is not met, and I benchmark to know if the set standard has been met" (Participant F).

“.... and the use of benchmarking system to know if I'm meeting up with the required standard" (Participant F).

\subsubsection{Performances}

"I make sure that lectures and symposium are organised for the staff from time to time, to update them to increase performance..." (Participant A).

"I depend on evidence based practice to improve my performance..." (Participant B).

"I also encourage my subordinates like I do, to engage in further studies and evidence based practice to sharpen their skills to promote quality care"'( Participant B).

".....in cases of poor performance, I address them accordingly, applying effective corrective measures for them to perform better in the future, (Participant C).

"Emm... Actually, I strategize my activities in other of priority, I ensure effective planning, setting a goal and working towards the achievement of the goal" (Participant B).

\subsection{Impact of effective care management}

Nurse leaders that were interview have proven to provide effective management of care in different ways and measures to enhance better healthcare outcome. Subthemes such as patient centred care, quality care, standard practice, care plan and reflective practice has been summed up to achieve impact of effective care management as a key theme. The nurses' views on the impact of effective management are narrated in the subthemes as below

\subsubsection{Patient centred care}

"Since effective care of patient is the expected performance in the healthcare sector, as a nurse leader I ensure effective nurse patient relationship" (Participant D).

"in ensuring effective management of patients in the ward. I apply the necessary skills and knowledge and ensure those activities that will improve patients' health"' (Participant D).

“....I ensure patient centred care approach is being practiced to provide effective and efficient care to influence better health outcome" (Participant D).

"...for effective management of care, I get the patients involved in their care, trying to know what the patients wants since it is a patient centred approach, so I ensure that the patients must be involved in whatever thing that is being done to them" (Participant F).

"My position as a nurse leader can affect better health outcome which is a quality care giving to patients, is by influencing the staff performance in all areas, by encouraging them to engage in the best practice, encouraging them to develop their own knowledge, then influence in the management and effective workforce" (Participant F).

"The relationship among staffs is centred in the patients' best interest" (Participant G).

\subsubsection{Quality and standard practice}

"To me, nursing leadership means someone that is experienced, skilled and has the capacity to carry followers along in their course of duty to attain a standard goal, so that the quality of care given to their patients is of a higher standard and better quality, to provide quality care" (Participant B).

"I ensure quality and standard care by assigning the tasks to the right people" (Participant B).

"My role as a nurse leader is a very enormous role focused on ensuring and providing standard care across the healthcare setting that I work for"'( Participant A).

".... making corrections when necessary to enhance quality in the care being delivered" (Participant $\mathrm{C}$ ).

"To ensure quality care, I constantly evaluate our activities, evaluating the effectiveness of the things we've done" (Participant D).

\subsubsection{Care plan}

"To ensure quality care, I make sure the care plan of the patients must be strictly followed through monitoring and supervision"' (Participant B).

\subsubsection{Reflective practice}

"....I depend on the reflective models I use the reflective models a lot, to reflect on every activity, every care, everything that I do and we do as a team every day, and possibly look for where improvement is highly needed" (Participant A).

\subsection{Impact of emotional intelligence}

Emotional intelligence has been identified among the nurses to enhance better leadership outcome. The impact of emotional intelligence was derived from the emotional issues and encouragements addressed by the nurses. Below is the information given by the participants regarding emotional intelligence.

\subsubsection{Encouragements}

"I always encourage my staff through affecting their emotions in order to make sure that work is perfectly done" (Participant A).

\subsubsection{Personal issues}

"As a nurse leader, I control the emotions of my staff directing them towards the expected goal” (Participant A).

\subsection{Impact of managerial skills}

Majority of the participants have demonstrated high engagement in managerial skills to achieve better health outcome. In applying the required managerial skills, subthemes such as teamwork, skill mix and 
availability, and discipline have been identified which resulted in the key theme which is impact of managerial skills. The important information given by the participant are discussed under the subtheme;

\subsubsection{Teamwork}

“....my team understands the importance of working with other members of the healthcare team for the benefit of the patients" (Participant B).

"Emm...for organisational goal to be achieved, a nurse leader cannot work in isolation, therefore, he/she has to carry his team members along, because the team members should be treated as an asset of inestimable value, if you treat your team members that way, they tend to give you their best" (Participant B).

\section{"I ensure effective teamwork" (Participant C).}

"I ensure effective teamwork and I also ensure good relationship between me and other staffs and as well as between staffs to make a better teamwork and to enhance better health outcome through performance, teamwork is very essential which is fostered by good relationship' (Participant C).

"I encourage teamwork, and make sure all the affairs are being coordinated effectively to ensure quality care" (Participant D).

\subsubsection{Skill mix and staff availability}

“....also assigning nurses to certain patients to ensure adequate skill mix allocation” (Participant B).

"Basically, nurses are assigned according to their skills" (Participant B).

"....my role as a nurse leader is to ensure that I have the right staff to balance with the available patients that I have in my ward, and to make sure that I have all the necessary and sufficient resources that can take care of the patients so that my staff will be able to work effectively and efficiently and in order to avoid any form of harm or any error when caring for the patients" (Participant C).

"I ensure adequate skill mix for better performance in the care of patients, because maintaining adequate skill mix is very critical in the ward" (Participant C).

\subsubsection{Discipline}

"I give appropriate punishment to discipline any misconduct" (Participant E).

"I will say my relationship influences positive outcome because people are deterred by the punishment they might get if they did not do their part" (Participant E).

\subsubsection{Organising and coordinating}

"and make sure all the affairs are being coordinated effectively to ensure quality care" (Participant D).

"I ensure that everything is done in an organised systematic way to get a good outcome" (Participant $\mathrm{H}$ ).

"My role as a nurse leader falls under several headings as follows, supervisory, coordinating of affairs and management, so in the supervisory role, I ensure that everybody is doing what they are supposed to do at the proper time and for the right patient" (Participant $\mathrm{H}$ ).

\subsubsection{Provision of needs}

"I also plan some incentives for them to motivate them" (Participant A).

"....also sending out requisition for materials that need to be use" (Participant B).

“....both human resources and non-human resources is provided for the effectiveness of the quality of care that will be given to the patients and in order to have a better health outcome for the patients" (Participant B).

“....in order to have better health outcome, I ensure adequate resources. Human resource is very essential especially balancing nurse-patient ratio, to ensure quality care is rendered" (Participant C).

\subsection{Impact of leadership roles}

The impact of leadership roles and skills is one of the significant key themes, and has the most emerged subthemes from the interview data. Participants were able to give different ideas on how their roles and skills can impact to the success of achieve a better health outcome in the care setting. Subthemes have been identified from the information gotten from the participants. The identified subthemes includes impartial, mentor, transparency, role model, delegation of duties, supervision, giving instructions, monitoring, corrective measures, prioritizing activities, working towards a set target, responsibility and accountability and strategizing activities. The verbatim quotes are as below;

\subsubsection{Role model and mentor}

"Humm... Nursing leadership role is a more or less like a mentorship role because you don't just be a leader, but you also show them how to do things perfectly, emm... you teach them how to do it and also encourage them to keep doing it and ensure that it is being done in the proper and standard way" (Participant A).

'they feel I'm someone that's very skilled and professional in my work, and a few of them, I think aspires to be like me, meaning they take me as a role model. They have trust in me and they take my leadership as effective" (Participant B).

"Yeah, I believe in playing the part of a role model, where I can set examples for others to follow. Therefore, as a nurse leader, the mode of influence to my subordinate is to care for my patients in a standard way for my subordinates to follow'. (Participant C).

\subsubsection{Supervision}

"I am there to oversee and supervise everything that is happening, in order to have a better health outcome" (Participant C).

"Errm...to ensure the delivery of quality care, I have to know how the staff under me carry out their duties, be able to supervise them in the care they give to the patients. By supervising them, I ensure they are doing the right things" (Participant $\mathrm{C}$ ).

"if I can't carry out the supervision alone, I delegate a more senior staff to carry out the supervisory role while I am engage with other duties" (Participant $\mathrm{H}$ ).

\subsubsection{Transparency}

"I achieve my organisational goal by doing my work in a judicial manner, in a sense of carrying out my duties honestly, transparently and properly", (Participant $\mathrm{H}$ ). 


\subsubsection{Monitoring}

"my leadership role involves giving directions and organising people, monitoring what they are doing" (Participant E).

"And what I do is to intensively monitor the progress of the activities, to make sure that whatever they are doing is in line with the goals we are aiming to achieve" (Participant E).

\subsubsection{Delegation of duties}

"I delegate a particular duty to a staff, making him/her responsible and accountable for it which also helps them in getting to a higher standard in their practice, it also makes them more responsible, being able to carry out a task effectively. They are being supervised and I check through the care plan to ensure things are done correctly" (Participant B).

"Delegation or assigning of roles is done based on skills and years or experience as well as the kind of job" (Participant B).

"When delegating duties, I ensure the right job is giving to the right person, according to skills, years of experience, qualification and capability to ensure all tasks delegated will be carried out effectively" (Participant D).

\subsubsection{Strategizing and prioritizing activities}

Emm... Actually, I strategize my activities in other of priority, I ensure effective planning, setting a goal and working towards the achievement of the goal. However, I try to influence my subordinate to work towards same goal to enhance better health outcome. (Participant B).

"I ensure the policies of the ward and the hospital are giving high priority" (Participant D).

"Ensuring that everything is done in an organised systematic way to get a good outcome" (Participant $\mathrm{H})$.

\subsubsection{Responsibility and accountability}

"my role as a nurse leader is a very enormous role focused on ensuring and providing standard care across the healthcare setting that I work for" (Participant A).

"My role as a nurse leader is to ensure the smooth running of the ward' (Participant B).

"My role as a nurse leader entails emm... taking care of the ward and making sure the duties are well covered" (Participant B).

"I delegate a particular duty to a staff, making him/her responsible and accountable for it which also helps them in getting to a higher standard in their practice, it also makes them more responsible, being able to carry out a task effectively. They are being supervised and I check through the care plan to ensure things are done correctly" (Participant B).

"In my position as a leader, I believe that nurses play a key role in making sure that patients gets the best possible care they can get in the hospital' (Participant F).

"my role as a leader should be to influence my staff to motivate them, to support them to make sure the work is being done because if it's not done, it will affect the patients, so my role is to make sure my staff carries out their duties and with the use of evidence based practice" (Participant G).

\subsubsection{Motivation}

"I appreciate them and I also plan some incentives for them to motivate them" (Participant A).

"To motivate my staff, I liaise with the management for them to be adequately remunerated accordingly" (Participant A).

"To motivate them in the ward, I give praises to those that are performing excellently for them to do more; this has been a great influence and motivation for better performance" (Participant B).

"The way I influence my subordinates is by motivating them, because everybody likes to be motivated, and I motivate them through appraisals, through positive comments that will encourage them to do the more" (Participant F).

" $m y$ role as a leader should be to influence my staff to motivate them, to support them to make sure the work is being done appropriately" (Participant G).

"....they are given incentives to motivate them and for them to put in more effort" (Participant H).

\section{Discussion}

In interpreting the findings of the study, the emerged categories or key themes will be analysed to give the final description of the results. However, to do this, the findings will be discussed or explained under the emerged key themes by supporting its explanations with the subthemes, quotes (increasing validity with verbatim quotes from the statements made by participants) and theories and arguments from the literature (Frost, 2011; Guest et al., 2012). The quotes to be taken from what the participants said, will be only those that are important to the interpretation as was supported by Hough (2009:40) who indicated that "quotes that best told the story" are selected to strengthen analysis. At this stage, to produce a final report the findings which are the key themes will be discussed one at a time;

\subsection{The impact of how nurses regard leadership}

The impact of how nurses regard leadership as a key theme has been presented with three subthemes such as influencing others, attaining a standard goal and overseeing all activities. The way nurse leaders regard leadership has been seen to have great impact in the way they influence others to attain a standard goal. However, there has been several meaning giving to leadership by the nurse leaders. This has been earlier emphasized by Greenberg (2013) and Mendenhall et al. (2013) that leadership is a phenomenon that does not have a universally agreed defining.

Nevertheless, a verbatim transcription has indicated that leadership is "the capacity to carry followers along in their course of duty to attain a standard goal, so that the quality of care given to their patients is of a higher standard" (Participant B). Another participant also added that "nursing leadership is about ensuring that everything is done in order to help the patient recover or in order to give good healthcare to the patients. Ensuring that everything is done in an organised systematic way to get a good outcome" (Participant $\mathrm{H})$.

Consequently, leadership is taking as a process and an act of overseeing all activities (Kano, 2012), Greenberg (2013) highlighted that activities are coordinated, directed and influenced within an organisation or group of people to achieve a set objective or target. This has agreed to the participant that indicated that nurse leadership is "to lead people in the right way" (Participant D). Additionally, Northouse (2012:1) as also cited that leadership is the "process whereby an individual influences a group of persons to achieve a common goal. Therefore, the goal of the nurse leaders is to influences others to achieve organisational goal which is a better healthcare outcome. According to Buscer et al. (2009) and Eneh et 
al. (2012), this has triggered the increase need for nurse leaders to provide quality and evidence based care.

\subsection{Impact of communication}

From the responses of the participants, communication has been seen as a major factor in the management of patients to achieve a better healthcare outcome. Good communication flow, transparency and mode of communication have been identified as the subthemes by the researcher In the findings, effective communication between staffs in a work place has been noted to enhance patient care as stated in the verbatim quote as below;

"the leader must be able to communicate properly with their subordinate, so that they will be able to take good care of the patient, and also be able to communicate with other healthcare professionals. With effective communication things will work fine, because a situation whereby there is no adequate communication the multidisciplinary team will not be able to express their feelings regarding patients' care" (Participant D) However, another participant has equally specified that "I ensure effective communication for things to be done in the proper manner" (Participant D). At the same time, there should be transparency in communication in the care of patients. Therefore, another participant proved that "also, $I$ ensure transparency in all levels of communication to enhance better patient care" (Participant D).

Since nursing of patients is a continues process (Meleis, 2010), nurse leaders who participated in the study emphasized on effective communication as a means of passing across patients care and need to enhance better outcome. Shannon and Weaver (1949) conceptual model of communication has also indicated that communication is the source of information transferred from one individual to another (Hamilton, 2013). According to Mortensen (2009) and Webb (2011), communication improves performance in healthcare practice. Therefore, better healthcare outcome is influenced by effective communication as the nurses leaders have proclaimed.

\subsection{Impact of interpersonal relationship}

The study has revealed how interpersonal relationship can impact in the care of a patient. Furthermore, it has also shown close relationship between communication and interpersonal relation. Cordial relationship, cooperativeness and rapport with co-workers emerged as subthemes to influence interpersonal relationship. Hence, the participants have indicated how interpersonal relationship through communication can influence performance in the verbatim transcription as below;

"With effective communication, things will work fine, because a situation whereby there is no adequate communication the multidisciplinary team will not be able to express their feelings regarding patients' care. Therefore, I maintain should be a good relationship to enhance good communication which will enhance management of care" (Participant D). As a matter of fact, a participant indicated that "relationship has a lot do with positive outcome, if there is no good and proper relationships there won't be proper communication; meaning there will be gap in communication. So as a leader I communicate properly with my subordinates, so that they will be able to take good care of the patient, and also be able to communicate with other healthcare professionals to enhance better healthcare outcome within the multidisciplinary team" (Participant D)

Therefore, nurse leaders have proven the ability to enhance patients' care by maintaining cooperativeness, cordial relationship and rapport to be able to influence better healthcare outcome within the nurses and the multidisciplinary healthcare team. According to the Nursing Leadership Institute Competency Model (2003), building interpersonal relationships among nurses and the interdisciplinary team is crucial in terms of developing competency in nursing profession. According to Finkelman and Kenner (2012), this will enhance effectiveness in collaborating, communication and managing conflict in the healthcare setting. Therefore, the nurse leaders have shown competency in their performances as nurse leaders to enhance better healthcare outcome by maintaining good interpersonal relationship. However, Daft (2008) had earlier warned that nurse leaders should not only focus on how the job is done, because the job may not be done without building strong relationships with the followers and the interdisciplinary teams.

\subsection{Impact of leadership style}

Nurse leaders have shown increased knowledge in leadership styles and how they apply them to achieve a desirable outcome. This has been indicated in the verbatim quote as below;

"Sometimes, I apply the democratic style of leadership where I seek their opinion so that we can have better outcome by working together" (Participant C). According to another participant: "....sometimes I have to be democratic to involve them in decision making for them to feel responsible in the performance of their daily duties" (Participant $\mathrm{H}$ ). However, the nurse leaders have also indicated the help of applying autocratic leadership as quoted; "....sometimes I apply command which is an autocratic kind of leadership as the strategy to facilitate better performance" (Participant C).

Consequently, according to Lussier and Achua (2013), it is essential to involve subordinates in making decision for them to participate fully, having the responsibility to do according to their contribution. However, one-way communication is employed unlike the former which is two-way communication. The one-way communication is the autocratic kind of leadership where the leaders take decision and issue commands for action to be taken (Kelly, 2013). However, Lussier and Achua (2013) encouraged flexibility in applying leadership styles which supports the adoption of situational theory as the nurses applied leadership styles according situations indicate in below verbatim quote;

"To influence my subordinates, I tend to be flexible, using democratic leadership styles but sometimes I employ the autocratic style of leadership especially when things are supposed to be done in the right manner. Basically, the application of leadership styles depends on the situation at hand" (Participant B)

Essentially, the nurses' views have been supported by the Fielder's (1967) Contingency Theory which is among the contingency approaches to leadership. According to Kelly (2013), it is concerned with leadership effectiveness. In this theory, the leaders' behaviour is determined by the situation (Comack, 2012) as the nurses have declared. Therefore, nurses have demonstrated high knowledge in application leadership style in influencing better health outcome.

\subsection{Impact of training}

Regular training and lifelong learning have been identified as subtheme to impact of training as a key theme. Impact of training has been identified by the participants as a measure for improved performance. It has been indicated that training enhances clinical knowledge and skills as well as leadership knowledge and skills. Therefore, training has a lot to do with better healthcare outcome in the healthcare setting as shown in the verbatim quotes below;

"Nurse leaders affect health outcome by encouraging staff to attend regular training and courses to attain the trend in the profession by acquiring the required skills to be applied in practice which assures quality care and better health outcome" (Participant B). Again, "I also encourage them to undergo professional specialisation to be able to master skills in a particular area to be able to apply the best practice to enhance better outcome" (Participant B). Further verbatim quotes states that "I improve my performance through attending workshops and trainings on leadership and professional skills” (Participant D). “...and also engage in lifelong learning (Participant B).

According to Adeniyi (2010), to face the challenges and meet with the trend in development of nursing practice, nurses need to keep the knowledge and skills up-to-date through training. Social Cognitive Theory has also indicated that humans are influenced by training through what they have learned to enhance effectiveness (Westwood, 2013). Consequently, Mcdikkoh (2010) emphasized that nurse leaders should 
attend developmental programs and leadership seminars to be able to work towards organisational goals. Therefore, nurse leaders have shown competency in their role by adopting improvement strategies through attending training and sending their subordinates for training to enhance performance and influence better health outcome

\subsection{Impact of proficiency in practice}

This study has shown how competency of the nurse leaders can enhance better healthcare outcome through the application of best practice and improved clinical and leadership skills. Nurse leaders have therefore emphasized on their performances, being able to do those things that will enhance achieving organisational goal as quoted;

"Since the all healthcare settings are to achieve a better healthcare outcome, so as the nurse leader I require all necessary skill to attain better health outcome in the healthcare setting" (Participant C)

"...I must be able to see that the quality of care the patients are receiving are really the first class care, they must get a better quality care from the nurses" (Participant G)

"Competency is promoted, therefore, case of negligence is not to be tolerated in the ward, cases of negligence should be reported, because they have actually led to thousands of death as we have seen in previous report" (Participant B)

Nurses have indicated that without competency in practice, quality care will be compromised. According to Benner (1984) stages of clinica competency, nurses move from novice to experts in nursing leadership and practice. Hence, they engage in those activities that will promote quality care to ensure better health outcome. To support the nurses views, Nursing Leadership Institute Competency Model (2003) and Bish et al. (2013) emphasized that competency in nursing leadership is concerned with the skills in nursing practice. Hence, the competencies of nurse leaders are very critical in their day-to-day activities (Abiodun, 2010) to increase performance enhance health and wellbeing (Supamanee et al. 2011).

\subsection{Impact of improvement strategies}

Nurse leaders have device strategies to improve in their practice. They have shown the impact of improvement strategies as a means to provide quality healthcare to enhance better healthcare outcome. The impact of improvement strategies as theme was derived from the following subthemes such as appraisals, benchmarking and performance. Therefore, to improve their performances, they undergo appraisals and benchmarking;

"Another way of improving my performance is also to get feedbacks from staff appraisals and patients' feedbacks from the suggestion box. What they say about me and things they feel are not right will be acted upon" (Participant G).

"ermm...yeah, I evaluate my performances by appraisals according to our set goal, like I said, there is a set goal for the ward as well as for each patient, we carry out an appraisal and check if the goals were met. (Participant B)

"I make sure that lectures and symposium are organised for the staff from time to time, to update them to increase performance..." (Participant A)

I also encourage my subordinates like I do, to engage in further studies and evidence based practice to sharpen their skills to promote quality care" ( Participant B)

To support the nurse leaders' strategies for improvement, Eneh et al (2012) stressed that trainings, feedbacks, appraisals benchmarking and other response heightens a better healthcare practice. In terms of benchmarking, the Perry's (1970) model of intellectual development, development comes by weighing the best evidence from benchmarking and adjusting to the best practice thereby ensuring improvement and development (Perry, 2013). Therefore, excellent service delivery is enriched by the nurse leaders through adopting the above various improvement strategies as in the verbatim quotes. Hence, they are fit to face the challenges of the contemporary nursing practice. Moreover, Cummings (2012) have highlighted nursing leaders brings positive outcome to nursing practice.

\subsection{Impact of effective care management}

According to Benner (1984), effective management of care requires being an expert with a specialized knowledge in care. In the interview, nurse leaders had verbalised being skilled enough in coordinating patients' care which is geared towards providing enhancing better health outcome.

"...for effective management of care, I get the patients involved in their care, trying to know what the patients wants since it is a patient centred approach, so I ensure that the patients must be involved in whatever thing that is being done to them" (Participant F). Another participant also indicated that "in ensuring effective management of patients in the ward. I apply the necessary skills and knowledge and ensure those activities that will improve patients' health" (Participant D). Therefore, participant added, "to ensure quality care, I make sure the care plan of the patients must be strictly followed through monitoring and supervision" (Participant B). According to participant D, "to ensure quality care, I constantly evaluate our activities, evaluating the effectiveness of the things we've done" (Participant D). Also to participant A, “...I depend on the reflective models I use the reflective models a lot, to reflect on every activity, every care, everything that I do and we do as a team every day, and possibly look for where improvement is highly needed"(Participant A)

According to the study, the essence of effective care management is to provide a quality care to patients/clients. Subsequently, the study highlights that ensuring quality and standard care, patient centred care, reflective practice and care plan of patients enhances effective care management. On the same vein, DoH (2010) and DoH (2011) showed that patient centred care approach is a standard approach to care to achieve a quality care. However, evaluation of care through reflection has been indicated to enhance improvement (Gibbs, 1988). However, Buscer et al. (2009) and Eneh et al. (2012) have recorded the influence of nurse leader in the provision of quality and evidence based care. Therefore, the responses of nurse leaders in providing quality care to impact on effective care management have been verified.

\subsection{Impact of emotional intelligence}

Nurse leaders have demonstrated applying emotional intelligence in their nursing practice. According to Chapman (2011), having emotional intelligence is being able to identify, control and assess ones emotion as well as that of others. The nurse leaders demonstrated emotional intelligence in their interview;

"As a nurse leader, I control the emotions of my staff directing them towards the expected goal” (Participant A)

"I always encourage my staff through affecting their emotions in order to make sure that work is perfectly done" (Participant A)

Emotional intelligence in nursing practice has been indicated to improve care if handled effectively (Doody and Doody, 2012). The study has shown how nurse leader effectively applied emotional intelligence to achieve better healthcare outcome. Moreover, it has been claimed that healthcare practice can be improved by developing qualities of having emotional intelligence (Moss, 2005; Roussel, 2011). Therefore, emotional intelligence qualities have been identified among the nurses to enhance better leadership outcome. Furthermore, Moss (2005) and Kelly and Tazbir (2013) elaborated that emotional intelligent nurse leaders are able to communicate effectively and share vision, manage conflicts, and inspire followers to make their vision a reality. 


\subsection{Impact of managerial skills}

The participants have established increased engagement in managerial skills to achieve better health outcome. In applying the required managerial skills, subthemes such as teamwork, skill mix and availability, and discipline have been identified which resulted in the key theme, which is impact of managerial skills.

\subsubsection{Teamwork}

The participants have identified the effectiveness of teamwork in a healthcare environment which is to work towards the enhancement of better healthcare outcome. The effectiveness of teamwork have been identified in the verbatim quotes as below;

"I ensure effective teamwork and I also ensure good relationship between me and other staffs and as well as between staffs to make a better teamwork and to enhance better health outcome through performance, teamwork is very essential which is fostered by good relationship" (Participant C).

"I encourage teamwork and make sure all the affairs are being coordinated effectively to ensure quality care" (Participant D).

The knowledge and skills of the nurse leaders that participated towards adopting teamwork approach has been support by Belbin's (1981) Team Roles Model, who emphasized the need for team work to achieve a common goal (Belbin, 2012). However, Adair (2011) Action Centred Leadership Model indicates that effective teamwork facilitates each team member to be responsible in their roles to perform a given task (Belbin, 2012). Hence, adopting teamwork approach has been indicated to improve performance thereby enhancing better healthcare outcome.

\subsubsection{Skill mix and staff availability}

Ensuring availability of staffs according to their different skills to fit in nurse-patient ratio has been identified as a major concept in the care of patients in the ward.

"I ensure adequate skill mix for better performance in the care of patients, because maintaining adequate skill mix is very critical in the ward" (Participant C)

"I assign nurses to certain patients to ensure adequate skill mix allocation" (Participant B)

"Basically, nurses are assigned according to their skills" (Participant B)

Caring has been identified in the Nursing Leadership Institute Competency Model (2003). Therefore, there is need to ensure adequate skill mix which is to meet with required patient needs. However, Skill mix is the combination of skills according to competency, and the mix of various levels staff within the multidisciplinary healthcare team (Buchan et al., 2002; Buchan et al., 2006). The study has revealed that nurse leader ensure adequate skill mix to foster improve patient care thereby enhancing better healthcare outcome.

\subsubsection{Discipline}

The study has identified discipline as a strategy to foster better performance among the nursing staff. The participants have therefore indicated the need for discipline through applicable punishment

"I give appropriate punishment to discipline any misconduct" (Participant E)

"I will say my relationship influences positive outcome because people are deterred by the punishment they might get if they did not do their part" (Participant E)

According to NMC (2008), nursing are responsible and accountable for their actions. Therefore, should be diligent in performing their duties However, appropriate punishment is given for any misconduct to enhance better performance thereby enhancing better healthcare outcome. Northouse (2012) and Todnem and Burnes (2013), argued that leaders should be able to apply different styles of leadership in different occasions such as applying discipline when necessary to ensure that followers act on the right direction of achieving the organisation's objectives. Moreover, Pitman (2009) outlined that the effect of power gives the leader the ability to influence the followers to achieve the organisational goals.

\subsubsection{Organising and coordinating}

Nurse leaders have demonstrated managerial skills including organising and coordinating to enhance effective patient care as indicated in verbatim quote;

"And I make sure all the affairs are being coordinated effectively to ensure quality care" (Participant D)

"I ensure that everything is done in an organised systematic way to get a good outcome" (Participant $\mathrm{H}$ )

"My role as a nurse leader falls under several headings as follows; supervisory, coordinating of affairs and management, so in the supervisory role, I ensure that everybody is doing what they are supposed to do at the proper time and for the right patient" (Participant $\mathrm{H}$ )

"Managerial role in nursing leadership has been identified as critical in the provision of effective, high-performing, and efficient patient care in the health care setting" (Chase, 2010:4). This is in accordance with the information given by the nurse leaders by identifying managerial role as an essential aspect in the delivery of healthcare service. Furthermore, Adair (2011) Action Centred Leadership Model has also identified some leadership functions such as organising, coordinating, controlling, and motivating that will enable the achievement of success in leadership, to attain competency according to Nursing Leadership Institute Competency Model (2003). Therefore, the nurse leaders' views on managerial role is an effective aspect of performing healthcare delivery services to enhance better healthcare outcome.

\subsubsection{Provision of needs}

Provision of the needs is also an essential aspect of nursing leadership as has been identified. Nurse leaders have indicated the importance of providing the required needs as below;

“....both human resources and non-human resources is provided for the effectiveness of the quality of care that will be given to the patients and in order to have a better health outcome for the patients" (Participant B)

"....in order to have better health outcome, I ensure adequate resources. Human resource is very essential especially balancing nurse-patient ratio, to ensure quality care is rendered" (Participant $\mathrm{C}$ )

According to Maslow's (1943) theory of need, the nurse leaders have indicated the prioritization of patients need as well as the needs of the staff to carry out their daily activities to enhance better healthcare outcome. The study have revealed that the nurse leader provide both human and non-human resources in the performance of their daily activities to enhance quality care. Furthermore, Pari and Terhaar (2011) emphasized on the need for nurse leaders to ensure availability of resources to enhance patients' care and Donlevy and Walker (2011) also emphasized on need of providing the needs of the followers to gain their participation. Therefore, the provision of human and non-human resources is essential for better healthcare outcome.

\subsubsection{Impact of leadership role}

Basically, leadership role in nursing practice is to improve better patient outcome (Eneh et al., 2012) through the subthemes such as supervision, monitoring, effective delegation of duties, strategizing and prioritizing activities and being responsible and accountable. This is to impact staff engagement and reduce errors in patient care (Kelly, 2012). The study has shown that nurse leader perform the roles of a mentor to enhance patient 
care. In their response, they ascertained that their role as a leader is not just to lead but to also perform the role of a mentor and a role model to ensure things are being done in a proper and standard manner to ensure better health outcome. Mentoring is essential in nursing because it strengthens the relationship between the nurse leader and the other staff (Stewart, 2009; Kuwabara, 2009). NMC (2008) emphasized that mentoring fosters clinical competency, where the mentee moves from a novice to an expert in the clinical area (Benner, 1984). A mentor also performs the role of a supervisor (Giltinane, 2013) as the participants have rightly mentioned they perform a supervisory role to ensure things are done in a standard way. The study have also shown that nurse leaders perform delegation, monitoring, motivate subordinates, strategizing and prioritizing activity role to ensure better healthcare outcome.

"To motivate them in the ward, I give praises and incentives to those that are performing excellently for them to do more; this has been a great influence and motivation for better performance" (Participant B).

"The way I influence my subordinates is by motivating them, because everybody likes to be motivated, and I motivate them through appraisals, through positive comments that will encourage them to do the more" (Participant F).

The nurses have pointed out that motivating subordinate as a good way of influencing them to perform better and bring out their best in caring for patients. Abraham Maslow's (1943) Hierarchy of needs emphasized that humans are motivated by providing their basic needs which influence them to increase their performance to provide a higher need (Cadieux, 2011). Furthermore, delegation of duties effectively has also been indicated to improve care as in the verbatim quotes below;

"I delegate a particular duty to a staff, making him/her responsible and accountable for it which also helps them in getting to a higher standard in their practice; it also makes them more responsible, being able to carry out a task effectively. They are being supervised and I check through the care plan to ensure things are done correctly" (Participant B)

The study has revealed that delegation of duty gives responsibility and accountability to the nurses which attractions greater performance to enhance better healthcare outcome. Rao and Krishna (2009) has also cited that effective delegation improves performance in workplace. However, the study has also indicated that after delegation, the nurses play a monitoring role to supervise the delegated duties.

"And what I do is to intensively monitor the progress of the activities, to make sure that whatever they are doing is in line with the goals we are aiming to achieve" (Participant E)

Emm... Actually, I strategize my activities in other of priority, I ensure effective planning, setting a goal and working towards the achievement of the goal. However, I try to influence my subordinate to work towards same goal to enhance better health outcome. (Participant B).

However, when delegating and monitoring, the study showed that the nurse leaders strategizes and prioritizes their activities to be able to influence their subordinates to work towards the expected outcome which is a better healthcare outcome. Moreover, Adeniyi (2010) state that nurse leaders should strive for effective leadership to accomplish the goals and objectives of the organisation. Generally, the Nursing Leadership Institute Competency Model (2003) has outline various competency in nursing leadership to achieve effective leadership outcome which includes personal mastery, financial management, interpersonal effectiveness, effective caring, human resource management and systems thinking. This study has discovered these competencies among nurse leader to enhance better healthcare outcome.

\section{Conclusion}

Conclusively, the chapter has discussed the findings and produced the final report to complete the last stage of thematic analysis according to
Braun and Clarke (2006) and Carollo (2012). The findings have been discussed under the emerged key themes that where generated from the subthemes. Generally, this final report was enhanced supported by theory and literature to analyse the interview data. The final report as above has given us the result of the study which is the perception of nurses towards regarding nurse leadership as an influential factor to better healthcare outcome. The above results have shown that nurse leadership has a prodigious relationship in providing better healthcare outcome.

\section{References}

Abiodun, R. (2010). Leadership behaviour impact on employee's Loyalty, engagement and organisational performance. Bloomington. AuthorHouse.

Adair, J. (2011). Effective teambuilding: How to make a winning team. Oxford. Pan Books.

Adeniyi, M. A. (2010). Effective leadership management: An integration of styles, skills and character for today's CEOs. Bloomington. AuthorHouse.

Armstrong, P., Peckler, B., Pilkinton-Ching, J., McQuade, D., \& Rogan, A. (2020). Effect of simulation training on nurse leadership in a shared leadership model for cardiopulmonary resuscitation in the emergency department. Emergency Medicine Australasia, early view. https://doi.org/10.1111/1742-6723.13605

Beck, C. T. (2013). Routledge international handbook of qualitative nursing research. New York. Routledge. https://doi.org/10.4324/9780203409527

Belbin, M. (2012). Team roles at work. Oxford. ButterworthHeinemann https://doi.org/10.4324/9780080963242

Benner, P. (1984). From novice to expert, excellence and power in clinical nursing practice. Menlo Park. Addison-Wesley Publishing Company. https://doi.org/10.1097/00000446-198412000-00025

Bigi, H. (2012). Journalism education between market dependence and social responsibility. An examination of trainee journalists. Switzerland. Haupt Berne.

Bish, M., Kenny, A. and Nay, R. (2012). A scoping review identifying contemporary issues in rural nursing leadership. Journal of Nursing Scholarship, Vol. 44, Iss. 4, Pp. 411-417. https://doi.org/10.1111/j.1547-5069.2012.01471.x

Boyatzis, R. E. (1998). Transforming Qualitative Information: Thematic Analysis and Code Development. California. Sage Publishing.

Braun, V. and Clarke, V. (2006). Using thematic analysis in psychology. Qualitative Research in Psychology, Vol. 3, Iss. 2, Pp. 77-101. https://doi.org/10.1191/1478088706qp063oa

Bryman, A. (2013). Doing research in organizations. London. Routledge. https://doi.org/10.4324/9780203385449

Buchan J, Maynard A. (2006). United Kingdom. In: Rechel B, Dubois C-A, McKee M, eds. The Health care workforce in Europe: learning from experience. Copenhagen, WHO Regional Office for Europe. Pp. 129-143. http://www.euro.who.int/Document/E89156.pdf, (Accessed 11/09/2013).

Buchan, J., and Dal, P. M. R. (2002). Skill-mix in the health-care workforce: reviewing the evidence. Bulletin of the World Health Organization, Vol. 80, Iss. 7, Pp. 575-580.

Buscer, A., Sivertsen, B. and White, J. (2009). Nurses and Midwives: A Force for Health. Survey on the Situation of Nursing and Midwifery in the Member States of the European Region of the World Health Organization 2009 (online). WHO. http://www.euro.who.int/_data/assets/pdf_file/0019/114157/ E93980.pdf, (Accessed 17/07/2013).

Cadieux, T. J. (2011). How passion relates to performance: A study of consultant civil engineers. Florida. Universal Publisher.

Carollo, B. (2012). Luxury Brands and the Economic Recession. London. Grin

Chapman, M. (2011). Emotional intelligence pocketbook. 2nd Edition. Aylesford. Management Pocketsbooks Limited. 
Chase, L. K. (2010). Nurse manager competencies. http://ir.uiowa.edu/etd/2681 (Accessed 11/09/2013).

Comack, M. (2012). A journey of leadership: From bedside nurse to chief executive officer. Nursing Administration Quarterly, Vol. 36, Iss. 1, Pp. 29-34. https://doi.org/10.1097/NAQ.0b013e318238b9fa

Cruz, E. V. and Higginbottom, G. (2013). The use of focused ethnography in nursing research. Nurse Researcher, Vol. 20, Iss. 4, Pp. 36-43. https://doi.org/10.7748/nr2013.03.20.4.36.e305

Cummings, G. (2011). The call for leadership to influence patient outcomes. Nursing Leadership, Vol. 1, Pp. 22-25. https://doi.org/10.12927/cjnl.2011.22459

Cummings, G. G., Lee, S., Tate, K., Penconek, T., Micaroni, S. P. M., Paananen, T., \& Chatterjee, G. E. (2021). The essentials of nursing leadership: A systematic review of factors and educational interventions influencing nursing leadership International Journal of Nursing Studies, 115, 103842 https://doi.org/10.1016/j.ijnurstu.2020.103842

Cummings, G. G., MacGregor, T., Davey, M., Lee, H., Wong, C., Lo, E. and Stafford, E. (2009). Leadership styles and outcome patterns for the nursing workforce and work environment: A systematic review. International Journal of Nursing Studies, Vol. 47, Iss. 3, Pp. 363-385. https://doi.org/10.1016/j.ijnurstu.2009.08.006

Daft, R. L. (2008). The Leadership Experience. 4th Edition. Mason. Thompson Higher Education.

Denscombe, M. (2010). The Good Research Guide: For Small-scale Social Research Projects. 4th Edition. Berkshire. Open University Press.

Donlevy, J. K. and Walker, K. D. (2011). Working through ethics in education and leadership: Theory, analysis, plays, cases, poems, prose, and speeches. Rotterdam. Sense Publishers.

Doody, O. and Doody, C. (2012). Transformational leadership in nursing practice. British Journal of Nursing, Vol. 21. Iss. 20, Pp. 1212-1218. https://doi.org/10.12968/bjon.2012.21.20.1212

Edmonstone, J. (2008). Clinical Leadership: The elephant in the room. www3.interscience. wiley.com/journal/121384179/abstract (accessed 22/06/2013).

Edwards, A. and Skinner, J. (2009). Qualitative Research in Sport Management. Oxford. Elsevier Limited.

Eneh, V. O., Vehvilainen-Julkunen, K. and Kvist, T. (2012). Nursing leadership practices as perceived by Finnish nursing staff: high ethics, less feedback and rewards. Journal of Nursing Management, Vol. 20, Pp. 159-169. https://doi.org/10.1111/j.1365-2834.2011.01373.x

Ezeakor, A. (2013). All alone: The psychosocial condition of Nigerian widows and childless women, implication for survivor's care. New York. Xlibris Corporation.

Feldman, H. R., Alexander, Ruiz, M., McBride, A., McClure, M. and Smith, T. D. (2012). Nursing Leadership: A concise encyclopaedia. New York. Springer Publishing Company.

Fetterman DM (2010) Ethnography Step by Step. Third edition., Thousand Oaks. Sage Publications.

Finkelman, A. and Kenner, C. (2012). Professional Nursing Concepts: Competencies for Quality Leadership. New York. Jones and Bartlett Publishers.

Folkestad, B. (2008). Analysing interview data possibilities and challenges. London. Eurosphere.

http://www.eurosphere.uib.no/knowledgebase/workingpapers.htm (Acccessed 20/08/2013).

Frost, N. (2011). Qualitative research methods in psychology combining core approaches. Berkshire. Open University Press.

Gerrish, K. and Lacey, A. (2013). The Research Process in Nursing. 6th Edition. Oxford. Blackwell Publishing Company.

Giltinane, C. L. (2013). Leadership styles and theories. Nursing Standard, Vol. 27, Iss. 41, Pp. 35-39. https://doi.org/10.7748/ns2013.06.27.41.35.e7565

Greenberg, J. (2013). Organizational behaviour: the state of the science. New Jersey. Lawrence Erlbaum Associates.
Guest, G., MacQueen, K. M. and Namey, E. E. (2012). Applied thematic analysis. London. Sage. https://doi.org/10.4135/9781483384436

Hamilton, C. (2013). Communicating for results: A guide for business and the professions. 10th Edition. London. Blackwell.

Hammersley, M. and Traianou, A. (2012). Ethics in Qualitative Research: Controversies and Contexts. London. Sage. https://doi.org/10.4135/9781473957619

Hickey, M. and Kritek, P. B. (2012). Change leadership in nursing: how change occur in a complex hospital system. New York. Springer Publishing Company.

Holloway, I. and Wheeler, S. (2013). Qualitative research in the nursing and healthcare. 3rd Edition. New York. Wiley-Blackwell.

Hough, D. L. (2009). Research supporting middle grades practice. New York. IAP-Information Age Publishing.

Houghton, C. E., Casey, D., Shaw, D. and Murphy, K. (2010). Ethical challenges in qualitative research: examples from practice. Nurse Researcher, Vol. 18, Iss. 1, Pp. 1-18. https://doi.org/10.7748/nr2010.10.18.1.15.c8044

Kano, E. (2012). Leadership styles and school performance. London. Grin.

Kelly, P. (2012). Nursing leadership and management. 3rd Edition. New York. Cengage Learning.

Kelly, P. (2013). Essentials of nursing leadership and management. 3rd Edition. New York. Delmar Health Care.

Kelly, P. and Tazbir, J. (2013). Essentials of nursing leadership and management. 3rd Edition. London. Delmar Health Care.

Klenke, K. (2008). Qualitative research in the study of leadership. Bingley. Emerald Group Publishing Limited.

Kolb, S. M. (2012). Grounded theory and the constant comparative method: Valid research strategies for educators. Journal of Emerging Trends in Educational Research and Policy Studies, Vol. 3, Iss. 1, Pp. 83-86.

Kuwabara, Y. (2009). Mentorship in the Japanese Nursing Education Community. Asian Nursing Research, Vol. 3, Iss. 2, Pp. 81 - 89. https://doi.org/10.1016/S1976-1317(09)60019-0

Love, K. (2012). Ethics in social research. Bingley. Emerald Group Publishing Limited

Lussier, R. N. and Achua, C. F. (2013). Leadership: Theory, application, skill development. 5th Edition. Cincinnati. SouthWestern College Publishing.

Lyons, E. and Coyle, A. (2007). Analysing qualitative data in psychology. London. SAGE Publication Limited. https://doi.org/10.4135/9781446207536

Mcdikkoh, D. M. N. (2010). The Nigerian health system's debacle and failure. New York. Xlibris Corporation.

Meleis, A. I. (2010). Transitions Theory: Middle Range and Situation Specific Theories in Nursing. New York. Springer Publishing Company.

Mendenhall, M. E.,Osland, J., Bird, A., Oddou, G. R., Maznevski, M L., Stevens, M. and Stahl, G. K. (2013). Global leadership 2e: Research, practice, and development. New York. Routledge. https://doi.org/10.4324/9780203817865

Miller, T., Mauthner, M., Birch, M. and Jessop, J. (2012). Ethics in Qualitative Research. 2nd Edition. London. Sage. https://doi.org/10.4135/9781473913912

Morgan-Trimmer, S., Wood, F. Ethnographic methods for process evaluations of complex health behaviour interventions. Trials 17 232 (2016). https://doi.org/10.1186/s13063-016-1340-2. https://doi.org/10.1186/s13063-016-1340-2

Mortensen, C. D. (2009). Communication theory. 2nd Edition. New Jersey. Transaction Publishers.

Moss, M. T. (2005). The emotional intelligent nurse leader. San Francisco. Jossey-Bass.

Murchison, J. (2010). Ethnography essentials: designing, conducting, and presenting your research. San Francisco. Jossey-Bass.

Murphy, J. (2009). Role of clinical nurse leadership in improving patient care. Nursing Management, Vol. 16, Iss. 8, Pp. 26-28 https://doi.org/10.7748/nm2009.12.16.8.26.c7395 
NMC. (2008). Standards to support learning and assessment in practice. NMC standards for mentors, practice teachers and teachers. London, United Kingdom.

Northouse, P. G. (2010). Leadership: Theory and Practice. 5th Edition. Sage Publications.

Nursing Leadership Institute. (2003). The nursing leadership institute competency model. http://www.fau.edu/nli/model2.pdf (Accessed 19/07/2013)

Perry, W. G. (2013). Forms of ethical and intellectual development in the college years: A scheme. San Francisco: Jossey-Bass.

Quimby, E. (2012). Doing Qualitative Community Research: Lessons for Faculty, Students and the communities. Danvers. Bentham. https://doi.org/10.2174/97816080525851120101

Rao, V. S. P. and Krishna, V. H. (2009). Management: Text and Cases. New Delhi. Excel Books.

Rapport, F. (2013). New qualitative methodologies in health and social care research. London. Routledge.

Ray, A. (2012). The Methodology of Sampling and Purposive Sampling. London. Grin.

Roussel, L. (2011). Management and leadership for nurse administrators. 6th Edition. London. Jones and Bartlett.

Rowles, G. D. and Schoenberg, N. E. (2002). Qualitative Gerontology: A Contemporary Perspective. 2nd Edition. New York. Springer Publishing Company.

Saini, M. and Shlonsky, A. (2012). Systematic synthesis of qualitative research. Oxford. Oxford University Press. https://doi.org/10.1093/acprof:oso/9780195387216.001.0001

Savin-Baden, M. and Major, C. H. (2010). New Approaches to Qualitative Research: Wisdom and Uncertainty. Oxon. Routledge. https://doi.org/10.4324/9780203849873

Scott-Jones, J. and Watt, S. (2010). Ethnography in social Science practice. Oxon. Routledge. https://doi.org/10.4324/9780203876305

Sfantou, D. F., Laliotis, A., Patelarou, A. E., Sifaki-Pistolla, D., Matalliotakis, M., \& Patelarou, E. (2017). Importance of Leadership Style towards Quality of Care Measures in Healthcare Settings: A Systematic Review. Healthcare (Basel, Switzerland), 5(4), 73. https://doi.org/10.3390/healthcare5040073

Silverman, D. (2011). Qualitative research. 3rd Edition. London. Sage Publications Limited.

Smith, J., Bekker, H. and Cheater, F. (2011). Theoretical versus pragmatic design in qualitative research. Nurse Researcher, Vol.
18, Iss. 2, Pp. 39 - 52

https://doi.org/10.7748/nr2011.01.18.2.39.c8283

Speziale, H. J. S. and Carpenter, D. R. (2007). Qualitative research in nursing: Advancing the humanistic imperative. 4th Edition. Philadelphia. Lippincott and Wilkins.

Speziale, H. S., Streubert, H. J. S. and Carpenter, D. R. (2011). Qualitative research in nursing: Advancing the humanistic imperative. 5th Edition. Philadelphia. Wolters Kluwer Health / Lippincott Williams and Wilkins.

Srivastava, A. and Thomson, S. B. (2009). Framework Analysis: A qualitative methodology for applied policy research. Journal of Administration and Governance, Vol. 4, Iss. 2, Pp. 72 - 79

Steen, M. and Roberts, T. (2011). The handbook of midwifery research West Essex. Blackwell Publishing.

Stewart, S. (2009). The mentor and the mentee: what is mentoring? http://sarah-stewart.blogspot.co.uk/2009/02/what-ismentoring.html (Accessed 12/09/2013).

Sue, D. W. (2010). Microaggressions and Marginality: Manifestation, Dynamics, and Impact. New Jersey. John Wiley and Sons, Inc.

Supamanee, T., Krairiksh, M., Singhakhumfu, L. and Turale, S. (2011). Preliminary clinical nursing leadership competency model: a qualitative study from Thailand. Vol. 13, Iss. 4, Pp. 433-439. https://doi.org/10.1111/j.1442-2018.2011.00649.x

Swansburg, R. J. (2002). Introduction to management and leadership for nurse managers. Ontario. Jones and Bartlett Publishers.

Takeuchi, A. (2008). Issues Related to Female Study-abroad Returnees: A Comparative Analysis of Japan Thailand. Ann Arbor. ProQuest LLC.

Todnem, R. and Burnes, B. (2013). Organizational change, leadership and ethics: Leading organizations towards sustainability. New York. Routledge.

Ulin, P. R., Robinson, E. T. and Tolley, E. E. (2012). Qualitative methods in public health: A field guide for applied research. San Francisco. Jossey-Bass.

Webb, L. (2011). Nursing: Communication Skills in Practice. Oxford Oxford University Press.

Westwood, P. (2013). Learning and learning difficulties: Approaches to teaching and assessment. London. David Fulton Publishers Limited. https://doi.org/10.4324/9780203823767

- Thank you for publishing with us. 